\title{
La reforma judicial y consolidación de la democracia*
}

\section{Judicial reform and consolidation of democracy}

Fecha de recepción: 28 de abril de 2011

Fecha de evaluación: 9 de junio de 2011 Fecha de aprobación: 21 de junio de 2011

\author{
Álvaro Echeverri Uruburu*
}

\section{RESUMEN}

En Colombia, la Constitución de 1991 transformó el sistema político y jurídico del país. Uno de los aspectos que más cambió fue el órgano judicial. Aparecieron nuevas instituciones, como la Corte Constitucional, el Consejo Superior de la Judicatura y la Fiscalía; adicionalmente, se establecieron las garantías para la defensa de los derechos consagrados en la Carta Política, el más importante la acción de tutela. El presente artículo reflexiona sobre las discusiones que se presentan frente a una posible reforma al poder judicial en Colombia.

Palabras clave: Administración de justicia, reforma, democracia

\section{ABSTRACT}

In Colombia, the constitution of 1991 transformed the political and legal system of the country. A major change occurred in the judiciary. New institutions emerged like the Constitutional Court, the Superior Council of the Judiciary and the District Attorney's Office; additionally guarantees for the rights enshrined in the constitution were established of which the most important was the writ for the protection of constitutional rights. This article reflects on the arguments presented in the face of a possible reform of the judiciary in Colombia.

Keywords: Administration of justice, reform, democracy

* Artículo de reflexión.

** Ex constituyente. Ex magistrado del Consejo Superior de la Judicatura. Actual Decano de la Facultad de Derecho de la Universidad Santo Tomás. 


\section{INTRODUCCIÓN}

Cada cierto tiempo se coloca en la agenda de los grandes problemas nacionales el tema de la necesidad de la reforma a la justicia, lo cual no deja de resultar paradójico si se tiene en cuenta que la administración de justicia en Colombia ha sufrido la más grande reforma en su aparato en virtud de la Constitución de 1991, sin duda la más profunda que se haya realizado en América Latina en los últimos veinte años.

De otra parte, el contexto político dentro del cual surge de nuevo la iniciativa de reforma no ha podido ser más desfavorable como consecuencia del enfrentamiento entre el anterior Presidente de la República y la Corte Suprema de Justicia, a raíz del hostigamiento contra sus integrantes de parte del más importante organismo de inteligencia del Estado, adscrito precisamente a la Presidencia. La gravedad inusitada de los hechos suscitó fundadas sospechas sobre los reales propósitos de la pretendida reforma a la justicia.

En un ambiente de distensión propiciado por el nuevo gobierno del Presidente Santos, este, con todo, ha insistido en la necesidad de sustanciales reformas al aparato judicial, cuyo proyecto debió aplazarse en búsqueda de consensos con las altas corporaciones de la rama.

En este punto, habría que preguntarse qué tan necesarias son estas reformas; si deben pasar por una enmienda de la Constitución o si, por el contrario, bastaría con la introducción de reformas legales que permitan un acceso más expedito de los ciudadanos a la administración de justicia, obteniendo decisiones prontas y justas a sus demandas.

Aquí, pues, se enfrentarían dos posiciones:

La de quienes sostienen que los problemas congénitos de la justicia, como la congestión judicial y el retardo en los procesos, poco tienen que ver con el diseño institucional del aparato judicial.
Para fundamentar esta posición, se alega, por ejemplo:

- Que mientras en 1994 se decidieron por todos los jueces y magistrados del país 1.497 procesos diariamente, en el 2009, con casi el mismo número de funcionarios, esta cifra pasó a 7.200.

- Con todo, a pesar del número significativo de procesos egresados -que denuncia un aumento de la productividad judicial-, la congestión judicial, el número de procesos acumulables permaneció casi idéntico al que existía a comienzos de la década (cerca de 3.000 .000 de procesos represados).

- La explicación a este fenómeno tiene que ver necesariamente con el incremento en la demanda de justicia, que se elevó en este periodo (1994-2009) en un $115 \%$.

- En contraposición al aumento de demanda, el presupuesto de la rama judicial no ha dejado de declinar durante estos mismos años, así:

Si en la década de los ochenta dicho presupuesto representaba el $0,6 \%$ del PIB, para alcanzar en la década de los noventa el $1 \%$ este vuelve a decaer durante el periodo presidencial que acaba de terminar, para situarse en el $0,3 \%$ en el 2008. Esto es muy por debajo de los niveles que tenía en la década de los setenta, que era del $0,55 \%$ del PIB.

La ausencia de recursos suficientes para la rama ha determinado que no haya sido posible aumentar en el número necesario la planta de jueces, magistrados y personal auxiliar, así como la introducción de medios tecnológicos a los despachos judiciales de todo el país que permitan hacer más eficiente el trabajo de esos despachos.

Para quienes defienden, por tanto, la no necesidad de una nueva reforma al aparato judicial por vía constitucional, bastaría:

- Un incremento del presupuesto de la rama a los niveles internacionales del 3\% del BID. 
- Una gestión más eficiente del aparato en su conjunto y de los despachos en particular.

- Simplificación y "estandarización" de procesos, así como la introducción de la oralidad en todas las jurisdicciones.

La otra posición, la de quienes sostienen la necesidad de reformas estructurales del aparato judicial y a algunas instituciones constitucionales como la tutela, parte de un diagnóstico pesimista acerca del funcionamiento de algunas de esas instituciones creadas por la Constitución de 1991.

Así, por ejemplo, los problemas de congestión y retardo de los procesos se atribuye, sin mayor análisis, a la ineficiencia de la Sala Administrativa del Consejo Superior de la Judicatura, como órgano superior de la Administración Judicial.

Otro aspecto sometido a crítica es el de la politización de la justicia en razón de la injerencia otorgada por la Constitución del 91 a las Altas Cortes para intervenir en la designación de algunos altos funcionarios del Estado, lo mismo que a nivel regional de parte de los tribunales seccionales.

Dicha politización se ve agravada por la designación que hace el Congreso de ternas enviadas por el Presidente de la República de los magistrados de la Sala Jurisdiccional Disciplinaria del Consejo Superior de la Judicatura, lo mismo que el Senado de los magistrados de la Corte Constitucional, una de cuyas ternas es provista igualmente por el Presidente de la República.

En uno y otro casos se sostiene que la elección por el Legislativo de estos magistrados pocas veces atiende a la calidad, trayectoria jurídica y probidad de los elegidos, sino a conveniencias de las fuerzas políticas mayoritarias, lo mismo que a la necesidad del ejecutivo de obtener respaldo para sus iniciativas mediante la satisfacción de las apetencias burocráticas de las mismas mayorías (reparto de "cuotas burocráticas" como factor de gobernabilidad).
Otro factor que denunciaría la crisis de la justicia tiene que ver con los conflictos permanentes entre los organismos de cierre de las distintas jurisdicciones y la Corte Constitucional en torno a la acción de tutela contra decisiones y sentencias judiciales.

Lo anterior, para no hablar de otros problemas que desde la propia vigencia de la Constitución de 1991 se han manifestado, como el "cruce de competencias" entre el Legislativo, el Consejo de Estado y la Corte Suprema de Justicia, en virtud de que los unos y los otros tienen facultades investigativas de tipo disciplinario y penal contra los miembros de una y otra corporación, o la crisis suscitada en torno al sistema de elección del Fiscal General de la Nación por las razones ya conocidas por el país. Para no hablar tampoco de las diferencias en el interior de la llamada Comisión Interinstitucional, que ha impedido la designación en propiedad del Director Administrativo Nacional de la rama.

También se habla de las dificultades en la confección de listas de candidatos para proveer los cargos vacantes en la Corte Suprema de Justicia y en el Consejo de Estado, agravadas en muchos casos por los sistemas de votación previstos en los reglamentos de ambas corporaciones.

Tanto en la visión de quienes no creen en la necesidad de una reforma estructural de la justicia como de quienes creemos lo contrario, el panorama de la Administración Judicial no puede calificarse como positivo y optimista.

Nuestra posición, por tanto, aceptando que los problemas de acceso a la justicia por parte de los ciudadanos no requiera necesariamente de una reforma integral al aparato de justicia, sino de reformas legales (aumento del presupuesto, creación de nuevas plazas que atiendan el incremento de demanda de justicia, la extensión de la oralidad a todas las jurisdicciones, la introducción de tecnologías en los despachos de todo el país, mejoramiento de la capacidad gerencial de los 
jueces y magistrados, la continuidad de los programas de actualización y perfeccionamiento de Ios funcionarios judiciales a través de la Escuela Judicial, etc.), si creemos en la urgencia de reformas estructurales a la rama, pero conservando el esquema democrático que para ella definió la Constitución de 1991.

\section{REFORMA A LA ADMINISTRACIÓN DE JUSTICIA - EL CONSEJO SUPERIOR DE LA JUDICATURA}

La propuesta de supresión del Consejo Superior de la Judicatura, hecha en el proyecto del gobierno Santos, incurre en dos graves errores: uno substancial que atenta contra el principio de autonomía e independencia de la rama, que quiso el Constituyente materializar a través de la idea de autogobierno de la misma por medio de un órgano propio e independiente de las otras ramas y órganos del Estado.

En la propuesta gubernamental, que busca crear un Consejo Superior Judicial, se rompe el principio de autonomía e independencia de la Rama Judicial, al conformar dicho cuerpo -así sea sin voto- con el Ministro de Justicia. Tampoco se aviene al concepto de racionalidad administrativa, que exige permanencia y continuidad en la resolución de los asuntos de la administración, el que los presidentes de las Altas Cortes tengan asiento en este organismo, sustrayéndolos de sus tareas propias que son las de administrar justicia y no de administrar la justicia.

Esta misma razón opera para que se suprima la llamada comisión interinstitucional de la rama, que lejos de servir para coordinar y armonizar propósitos a favor de la administración judicial, crea dualidades innecesarias y disfuncionalidades que entorpecen las actividades de aquella administración.

Un segundo error en el que se cae con el intento de supresión del Consejo Superior es el desconocimiento de la realidad, pues hace caso omiso de las realizaciones positivas, particularmente de la Sala Administrativa de dicho Consejo, como son:

- La terminación de los palacios de justicia en las capitales de departamentos y que el Fondo Rotatorio de Justicia no había sido capaz de adelantar y terminar.

- Las nuevas sedes, decorosas y dignas en casi todo el país, para los despachos judiciales.

- El manejo técnico de la carrera judicial.

- Los programas de formación, capacitación y actualización de los funcionarios judiciales, por medio de la Escuela Judicial Rodrigo Lara Bonilla.

- La dotación de los despachos y tribunales que no han vuelto a carecer de los medios y recursos para su funcionamiento.

- El establecimiento de sistemas de medición del rendimiento y calidad de la actividad judicial.

- La introducción de medios tecnológicos en algunos lugares, todavía incipiente por ausencia de recursos.

- La atención a políticas de descongestión.

- La organización racional en cuanto a la ubicación de los despachos judiciales, de acuerdo con las necesidades de demanda de justicia (el llamado mapa judicial).

- La existencia por primera vez en el país de estadísticas confiables y de estudios rigurosos sobre la administración de justicia.

- La dotación requerida para el funcionamiento del sistema acusatorio en la justicia penal.

Lo anterior no quiere decir que el Consejo Superior de la Judicatura en su Sala Administrativa no requiera de reformas para hacerlo mucho más gerencial, menos burocrático y por tanto más eficaz en su condición de gobierno administrativo de la rama.

\section{Algunas propuestas de reforma a la Sala Administrativa}

1. En cuanto a las calidades de sus magistrados. Por su función eminentemente administrativa, 
estos no deberían tener las mismas calidades que las de los magistrados de las otras Altas Cortes, debiéndose privilegiar el tener formación en administración, administración pública $y$ gerencia financiera.

2. Sistema de elección. Manteniendo el actual sistema de designación por la Corte Constitucional (1), Corte Suprema (2) y Consejo de Estado (3), los magistrados podrían ser elegidos en forma democrática por todos sus colegas, jueces y funcionarios de todo el país.

3. A la Sala Administrativa le correspondería el diseño y definición de las grandes políticas de la rama: plan de desarrollo; plan de inversiones; elaboración del presupuesto anual; la normatividad general para el funcionamiento de la carrera judicial y los criterios específicos para cada convocatoria; la creación y supresión de despachos judiciales en todo el país; la elaboración de listas de elegibles para llenar las vacantes en la Corte Suprema y en el Consejo de Estado.

4. El Director Nacional de Administración Judicial o Gerente de la rama debe ser el ejecutor de las políticas generales definidas por la Sala Administrativa del Consejo Superior de la Judicatura, lo mismo que del gasto con plena capacidad y autonomía contractual.

5. Reducción del staff burocrático de la Sala Administrativa, ya que los estudios, informes, estadísticas necesarias para su función serían suministrados por las unidades correspondientes de la Dirección Nacional de la Administración Judicial.

6. Supresión de las salas administrativas de los consejos seccionales por innecesarios en la medida en que duplican la labor que cumplen los directores seccionales de administración judicial y que en muchas ocasiones resultan entorpeciéndola.

\section{LA SALA DISCIPLINARIA DEL CONSEJO SUPERIOR}

Capítulo aparte merece este cuerpo del Consejo Superior de la Judicatura que, por razón a su sistema de elección mediante ternas, conformadas por el Presidente, es elegido por el Congreso de la República y ha recibido numerosas críticas en los medios de comunicación e incluso de otros órganos de la justicia.

En este punto valen dos claridades:

Es necesario que se entienda que el actual sistema de elección es la expresión del principio de la soberanía popular (art. $2^{\circ}$ de la C.P.), en el cual dos instancias de elección popular (Presidente y Congreso) intervienen en la designación de dichos magistrados.

Con todo, habría que establecer dos tipos de reforma a este sistema de elección:

- Liberar la escogencia de los candidatos de los afanes e intereses de los congresistas y del Ejecutivo. Para ello, el Presidente debería solicitar a las facultades de derecho reconocidas como de alta calidad, a la Academia Colombiana de Jurisprudencia y al Colegio Nacional de Abogados -si algún día llega a crearse-, candidatos a conformar dichas ternas. Solo de los nombres enviados por estas entidades el Presidente podrá confeccionar tales ternas.

- La elección por el Congreso deberá ser por mayoría calificada de las tres cuartas partes de sus miembros, a fin de garantizar el pluralismo ideológico y jurídico, tal como ocurre en otros sistemas políticos en los cuales el Parlamento elige a los miembros de altas cortes (Francia, Alemania).

De otra parte, los candidatos a desempeñarse como magistrados de la Sala Disciplinaria deberían 
acreditar haber pertenecido a la Rama Judicial al menos durante cinco años, no haber participado como candidatos a cargos de elección popular, ni haber sido miembros de directorios de partidos o movimientos políticos, ni haber hecho parte en forma alguna de una corporación de elección popular.

Este mismo sistema de designación, así como las inhabilidades, se podrían aplicar para el caso de la Corte Constitucional y para su designación por el Congreso.

La segunda claridad tiene que ser con la función disciplinaria. La voluntad del Constituyente para garantizar la independencia y autonomía de la Rama Judicial fue la de consagrar su autogobierno no solo en lo administrativo, sino en lo disciplinario. Por eso, atenta contra la autonomía de la rama entregar el juzgamiento de sus funcionarios a un órgano externo a ella -como es la Procuraduría-, tal como lo pretende la reforma presentada por el gobierno.

Por esta misma razón, resultó equivocada la decisión de la Corte Constitucional, en su momento, de trasladar la competencia disciplinaria para conocer de las faltas de los magistrados de las Altas Cortes y del Fiscal General de la Nación a la Comisión de Acusaciones de la Cámara de Representantes, cuya competencia se limita solamente a conductas calificadas como indignas o por razón de la comisión de delitos, de acuerdo con el modelo norteamericano, del cual lo tomó nuestro ordenamiento constitucional desde la Constitución del 86 -el llamado impeachment o juicio político-.

En estas condiciones, una sala jurisdiccionaldisciplinaria, renovada en cuanto a su origen pero manteniendo el principio de soberanía popular, tendría la legitimidad suficiente para el ejercicio de la función disciplinaria con respecto a todos los funcionarios judiciales, tal como lo dispuso - sin excepciones- el artículo 256 de la Constitución
Política. Igualmente, deberá intervenir en Sala Plena del Consejo Superior de la Judicatura (conformada por sus dos salas) en algunas decisiones administrativas, como sería la elaboración del plan de desarrollo de la rama, el presupuesto anual y la confección de listas de aspirantes para la Corte Suprema y el Consejo de Estado, pues no existe razón válida para que quienes siendo jueces de jueces, con el conocimiento de las situaciones éticas y de las necesidades de jueces y magistrados, no pudiesen intervenir en estas funciones, corrigiéndose en esta forma la decisión de la Corte Constitucional que en la práctica, al excluir a dicha Sala de todas las decisiones de administración judicial, conformó dos cuerpos separados que sólo actúan como un único organismo para elegir presidente del Consejo Superior.

\section{LA FISCALÍA GENERAL DE LA NACIÓN}

Hecha la opción por el Constituyente del 91 de ubicar la Fiscalía como organismo de la Rama Judicial, desechando las propuestas de que dependiese del Presidente de la República por los evidentes peligros de convertirla en instrumentos de persecución contra opositores y adversarios del gobierno de turno -como ocurrió con el DAS en la pasada administración-, no existe razón suficiente para que no sea la Corte la que de manera autónoma y atendiendo a las calidades que debe requerir el cargo, designe al Fiscal General.

De otra parte, nos preguntamos si no ha llegado la hora de efectuar una reestructuración de la Fiscalía, modificando su estatuto orgánico, a fin de ganarle mayor eficacia en sus funciones de investigación y acusación. Esta reestructuración deberá responder a preguntas tales como: ¿la organización de las unidades de fiscales de acuerdo con el tipo de delitos no conduce al recargo de unas unidades por la mayor ocurrencia de conductas de las cuales conocen y en cambio en otras una carga más liviana por la menor frecuencia de los delitos que deben investigar? ¿Resulta adecuada 
la estructura de secretarías comunes? ¿Qué pasa con la inmediación de la prueba cuando quienes la recaudan no se encuentran bajo la inmediata dependencia del investigador del caso? ¿Existen los medios y los programas para una formación realmente investigativa de los fiscales y del personal auxiliar? ¿Cómo lograr la coordinación efectiva entre la Fiscalía -que constitucionalmente tiene el monopolio de la investigación criminal- y otros organismos del Estado con funciones investigativas?

\section{REFORMAS A LA TUTELA}

Aceptada, de entrada, la razonabilidad de mantener la acción de tutela contra actuaciones judiciales, incluso las provenientes de los llamados "órganos de cierre" de las distintas jurisdicciones, resulta indispensable, sin embargo, someterla a principios y reglas claras que eliminen factores de fricción que durante tanto tiempo han enfrentado a la Corte Constitucional con otras instancias superiores de la Rama Judicial' ${ }^{1}$, pero, al mismo tiempo, permitir que esta acción siga cumpliendo su papel de instrumento de realización material, pronto e inmediato, de la Constitución y de los derechos fundamentales consagrados en ella. Estas nuevas reglas de creación legal, básicamente, pueden ser:

1. Establecer competencias especiales para resolver los casos de tutelas contra sentencias de las corporaciones de "cierre" de cada jurisdicción, disponiéndose que el fallo de una de sus salas o secciones se conozca en sala de tutela por

1 No contamos aquí con el espacio suficiente para argumentar a favor de la procedibilidad de la acción de tutela contra actuaciones judiciales. Para una justificación en el derecho comparado, particularmente alemán, cf. Lösing, Norbert, "El recurso de amparo constitucional en Alemania: similitudes y diferencias con la tutela colombiana. Revista de Derecho Público, No. 18, enero 2005, Consejo Superior de la Judicatura, Embajada de la República Francesa y GTZ.

Igualmente, para el caso colombiano, García Villegas, Mauricio y Uprimny, Rodrigo, "¿Qué hacer con la tutela contra sentencias?" Revista de la Academia Colombiana de Jurisprudencia, agosto de 2004. De los mismos autores, "¿Qué hacer con la tutela, ajuste o desmonte?", revista Derecho y Realidad, Facultad de Derecho, UPTC, 2003. Echeverri Uruburu, Álvaro, "La Constitución de 1991 y el principio de seguridad jurídica", Revista De la Academia Colombiana de Jurisprudencia, No. 332, agosto de 2006. otra de las salas o secciones de la respectiva corporación, para impedir que pueda ser anulada por un juez de inferior jerarquía. Esta solución parcialmente se recogió en el Decreto 1382 del 2000.

2. Cuando los motivos de la casación se refieran a violación de derechos fundamentales, esta se transmitirá por el procedimiento abreviado y sumario de la tutela (tutela-casación).

3. La tutela contra sentencias no podrá atacar la libertad de interpretación de la ley que posee el juez, siempre que esta fuere razonable y compatible con los principios, valores y mandatos constitucionales, lo mismo que con la interpretación que de estos haya efectuado la Corte Constitucional.

4. Tampoco la tutela podrá impugnar la libertad de valoración probatoria de la cual está investigado el juez, siempre y cuando tal valoración resulte razonable y provenga del sopesamiento de los distintos medios de prueba obrantes dentro del proceso.

5. La acción de tutela contra sentencias debe sujetarse a términos de caducidad, de suerte que dicha acción no quede abierta indefinidamente a la impugnación constitucional en desmedro de la seguridad jurídica. "Como lo dice la doctrina española, toda decisión judicial que ponga fin a un proceso no hace tránsito a cosa juzgada hasta que no haya transcurrido el plazo para interponer el recurso de amparo" ${ }^{2}$.

6. El derecho fundamental que se considere violado dentro de un proceso ordinario, que sirve de motivo a la interposición de la tutela, deberá haber sido alegado dentro de aquel al momento de su ocurrencia, salvo que tal violación se hubiere ocasionado durante el trámite de la sentencia. Como lo señalan Rodrigo Uprimny y Mauricio Villegas:

2 Pérez Tremps, Pablo. Citado. García Villegas, Mauricio y Uprimny, Rodrigo. Op. cit., p. 100. 
Esta exigencia tendría un doble propósito: a) fomentar la protección de los derechos fundamentales en el propio proceso ordinario, lo cual no solo estimula la constitucionalización del derecho, sino que además controla el incremento de demandas de tutela, y b) evitar que aquellos que pierdan un caso recurran a la tutela como mecanismo desesperado e inventen posteriormente el derecho violado $[. . .]^{3}$.

Como se observa, estas posibles reformas buscan normatizar el trámite de la acción de tutela contra sentencias judiciales, que infortunadamente quedó desregularizado por virtud de la Sentencia C-534 de 1992 de la Corte Constitucional, que declaró inexequible dicha acción contra decisiones judiciales, aunque exceptuándola para las situaciones calificables como "vías de hecho", concepto vago e indeterminado que se presta a interpretaciones subjetivas de los falladores en tutelas.

Con estos ajustes legales, posiblemente se lograría una seguridad jurídica mayor, compatible con la preeminencia absoluta que siempre debe mantener la Carta dentro de un Estado que se califique como constitucional y democrático.

\section{CONCLUSIONES}

Pensamos que una reforma a la justicia no se puede acometer ni producir mejores resultados que las anteriores sin un conocimiento suficiente de las instituciones que la conforman, sin una valoración correcta de su funcionalidad con respecto a los fines del Estado social de derecho.
Pero, igualmente, se requiere la aceptación autocrítica de sus avances y deficiencias de parte de los responsables de su gestión, dentro de lo que los norteamericanos Ilaman accountability y que aproximadamente podría traducirse como "rendición de cuentas". Ese espíritu autocrítico no parece acompañar a esos responsables siempre que se habla de reformas de la administración de justicia. Sin ese espíritu de aceptar los errores y deficiencias va a ser muy difícil exigir mayores esfuerzos presupuestales con destino a la justicia, lo mismo que obtener respaldo en torno a las reformas.

Finalmente, las reformas deben apuntar a profundizar las transformaciones democratizadoras de la Constitución del 91. El país no puede retroceder en el camino ganado hacia la democratización de sus instituciones, que fue precisamente el sello de esta Constitución.

Para nosotros cualquier reforma, incluida la judicial, deberá seguir apuntando a "construir sistemas de gobierno más equilibrados y con poderes judiciales fortalecidos", como lo señala el ex ministro y experto en estos temas del BID, Fernando Carrillo Flórez (1999). Un nuevo balance de poderes debe volver a ser, por tanto, uno de los rasgos distintivos del inacabado proceso democratizador iniciado por Colombia a partir de la Constitución vigente.

\section{REFERENCIAS}

Carrillo Flórez, F. (1999). Los retos de la reforma a la justicia en América Latina. En Reforma Judicial en América Latina. Una tarea inconclusa. Bogotá: Corporación Excelencia en la Justicia. 
de 2001. Consultado el 14 de febrero de 2010 en http://www.elcato.org/peregrinaje_buchanan.htm

Buchanan, J. y Brennan, G. (1985). La razón de las normas. Barcelona: Ed. Unión.

Calsamiglia, A. (1997). Racionalidad y eficiencia del derecho. México: Ed. Biblioteca de Ética, Filosofía del Derecho y Política.

Cusa, N. (1981). De qué manera saber es ignorar. En La docta ignorancia. Barcelona: Orbis.

Gauthier, D. (1994). La moral por acuerdo. BarceIona: Gedisa.

Harsanyi, J. (1975). Can the Maximin Principle serve as a Basis for Morality? A Critique of Jonh Rawls's Theory. En The American Political Science Review, (69).

Hume, D. (1997). Tratado de la naturaleza humana. México: Porrúa.

Krawietz, W. (2001). El concepto sociológico del derecho. México: Ed. Biblioteca de Ética, Filosofía del Derecho y Política.

Nozick, R. (1998). Anarquía, Estado y utopía. México: Fondo de Cultura Económica.

Posner, R. (1998). Utilitarismo, economía y teoría del derecho. En Estudios Públicos, 69. Universidad de Chile. Consultado el 10 de mayo de 2011 en www.cepchile.cl/dms/lang_1/doc_1088.html

Posner, R. (2000). El análisis económico del derecho. México: Fondo de Cultura Económica.

Rawls, J. (1997). Teoría de la justicia. México: Fondo de Cultura Económica.

Salcedo Megales, D. (1994). Elección social y desigualdad económica. Barcelona: Ed. Anthropos.

Sen, A. (1989). Sobre ética y economía. Madrid: Alianza.

Smith, A. (1997). Investigación sobre la naturaleza y causa de la riqueza de las naciones. México: Fondo de Cultura Económica.

Smith, A. (1997). La teoría de los sentimientos morales. Madrid: Alianza.

Veblen, T. (1992).Teoría de la clase ociosa. México: Fondo de Cultura Económica.

Zuleta, H. (1998). Razón y elección. México: Ed. Biblioteca de Ética, Filosofía del Derecho y Política.

Zuleta, H. (2010). Las instituciones y sus presupuestos de información en el orden social. Un enfoque económico. En revista Via Inveniendi Et ludicandi. Bogotá: Universidad Santo Tomás, Facultad de Derecho. 